\title{
LITERATURE
}

Q

\author{
Paulina Szymonek \\ University of Silesia, Poland \\ PAULINA.K.SZYMONEK@GMAIL.COM \\ HTTPS://ORCID.ORG/OOOO-0002-3251-0617
}

\section{Wolves in the City of Domesticated Women: The Queer Wild of Olivia Rosenthal}

\begin{abstract}
In 2009, in the city of Nantes, a pack of six wolves was released in a public park as part of Stéphane Thidet's art installation. A book of short stories accompanied the event. One of the authors involved was Olivia Rosenthal, who then incorporated her story into the novel Que font les rennes après Noël? (2010), in which captive wolves are reintroduced to the city. In this post-natural environment, animals provide a semblance of the wilderness for residents, yet remain enclosed in an extended zoo designed by man - an act that domesticates both sides of the fence by separating humans from wolves. Rosenthal's protagonist is one of such captives. Her life and the lives of animals are presented in parallel narratives. She grows up in a strictly controlled environment, and social standards are imposed on her. In a semi-autobiographical vein, Rosenthal explores issues of queer and gender marginalization as well as emancipation. At the same time, she seeks to dismantle the binary oppositions that place animals, women, and non-heteronormative persons on the other side of the fence. Relying on queer ecofeminist theory developed by Greta Gaard (1997) as well as trans-species urban theory formulated by Jennifer Wolch (1998), this paper argues that we should challenge the hierarchical approach to human and non-human life, as it silences differences and denies voice, rights, and agency to women, non-heteronormative persons, and animals. Tracing inspirations behind Olivia Rosenthal's novel, this paper also contemplates the ethics of using live animals in Stéphane Thidet's La Meute (2009) as well as Mircea Cantor's Deeparture (2005) - two art installations that place captive wolves in an artificial environment.
\end{abstract}

Keywords: wolves; animal studies; queer ecofeminism; trans-species urban theory 


\section{Introduction}

A blur of grey and black fur crosses the perfectly mowed grass and leaps over flowerbeds, leaving paw-prints in its wake. Fangs slice and sink into the red metal of a discarded Coca-Cola can. Noses dive into trash bins, taking in new, enticing smells. The camera clicks high above are clearly audible as a pair of yellow eyes stops to study the faces of those watching overhead. Soon, there are six pairs of eyes, six sets of paws and tails, carefully observed as the wolves run in the castle moats, jump over the benches, and munch on meat from Carrefour. The wolves are, in fact, animal actors provided by the trainer, Francky Estrade, for an art installation (Klan du Loup 2009). A metal fencing separates the animals from their audience. The spectatorship seems mutual, creating an uncanny sense of being so close to and yet so removed from the wild. For the wolves, it is as close to civilization as they can be.

Animals running in the heart of the city were real, but it was their symbolic presence that permeated the imagination of the audience, feeding on primal fears yet arousing the desire to belong with the wild. Inspired by the unusual spectacle, Olivia Rosenthal wove a story about those city wolves into her novel Que font les rennes après Noël? [To Leave with the Reindeer] (2010). Its structure presents the lives of animals and the life of the protagonist in parallel, each animal passage corresponding to a semi-autobiographical narrative of a woman discovering her own wildness and queer sexuality. The second-person narration is both personal and distanced: through the formal pronoun vous [you], the writer dissociates herself from the narrator and at the same time reaches out to the reader (Mai 2016, 56). While the protagonist speaks for herself, animals are not given a voice; instead, they are described through the eyes of those who care for, work with, and kill them. The lives and experiences of captive, laboratory, and farm animals are reported in a dispassionate tone, which makes their plight even more striking.

In the novel, the protagonist's journey toward emancipation unfolds through her relationship with animals: as a child, she yearns for a pet, which mirrors her dependence on her parents. After growing up, she no longer wants to own an animal but instead seeks to study various species and wishes to run free with the ones she considers wild. She soon realizes, however, that the wilderness she imagined may not exist, even beyond urban space. Whether these are herds of titular reindeer or wolves that roam outside the city, wild animals are often artificially managed. In fact, the protagonist herself trades one captivity for another: once free from her mother, she becomes dependent on her husband. Thus, she identifies with captive predators and appears to struggle with being domesticated, controlled, owned, and confined in an urban environment. Wolves resist captivity and so does she. The narrator of Que font les rennes après Noël? finds freedom, coming to terms with her queer sexuality, when she starts a relationship with another woman. Here, parallels between the woman and the animals end: Rosenthal's protagonist may be free, but the wolves remain captives. The author is aware that despite attempts to treat animals as equals, there remains a chasm between human and 
non-human others. In Que font les rennes après Noël? Rosenthal proposes to bridge it by deconstructing the opposition between nature and culture.

Relying on queer ecofeminist theory developed by Greta Gaard (1997) as well as trans-species urban theory formulated by Jennifer Wolch (1998), this paper argues that it is possible to challenge the hierarchical approach to human and non-human life, which silences differences and denies voice, rights, and agency to women, non-heteronormative persons, and animals. To seek equality, however, the perspective of those who cannot speak for themselves - at least in a traditional sense - should be considered. The wolves of Nantes act as a reminder that urban space is not exclusively human. Wild and domestic animals live alongside people whether we acknowledge their presence or not. Acknowledging their right to space constitutes the first step toward recognizing their subjectivity.

\section{The Artificial Wild}

In 2009, a pack of six captive wolves was released in the moats of the Castle of the Dukes of Brittany in the city of Nantes as part of Stéphane Thidet's installation. The moats, transformed into a public park, were thought to be a perfect spot for the pack - five grays and one black - with natural infrastructure providing additional aesthetic value as the metal fencing was mostly hidden from human view. Six authors were invited to write short stories that were included in La Meute [The Pack], a book that accompanied the event (Thidet 2009). The equal number of authors and wolves suggests a balance between human and animal worlds. In fact, it was a deliberate gesture: humans had to make room, at least for the duration of the event, for wild animals hunted to extinction on this territory. Wolves are inextricably linked to the human unconscious through myths, fears, and misconceptions inherited from the past and carried into the present. These canines lived alongside humans throughout most of our known history. Whether as competitors, a danger to livestock, or a companion species (in the form of the domesticated dog), the wolf is both a hated and revered creature who found its way into the beliefs and traditions of many cultures. The animal itself, although it does not directly threaten human life, remains a large, charismatic predator that deserves respect. Watching wolves roam the heart of modern urban life must have stirred something primal in those who yielded their own territory to these predators. And yet, they remained captives as the onlookers watched from a safe distance.

Olivia Rosenthal, one of the authors featured in La Meute, followed the logistics and procedures involved in bringing the pack to the castle moats, interviewing those in charge, including the wolf trainer (Cruse 2010). By incorporating these facts into her story, Rosenthal developed the basis for the novel, Que font les rennes après Noël? (2010). The novel begins not with wolves, however, but with a list of artificially-bred big-cat hybrids such as tigons, pumapards, and tiguars. These "denaturalized" animals possess "natural docility," which places them among the domesticated. Rosenthal writes that 
wolves are sometimes called hybrids to appear more tame and safe (2019, 13-14), but wolves are also interbred with dogs to produce hybrids. Their offspring is not considered wild, making it possible to acquire and keep them. In fact, wolf pups are often sold as wolfdog hybrids, while hybrids are sold as pure or high-percentage wolves to cater to demand. Those who are desperate for a captive wolf or a hybrid, however, wish to own a domesticated animal that only appears wild (Steinhart 1996).

In the novel, the story of captive wolves is narrated alongside scenes from the nameless protagonist's childhood. We learn that the girl would not care for toys, asking in vain for a pet. Still, she yearns to wield power over an animal in the form of an oppressive ownership that would mimic the relationship between herself and her parents. It is implied that she, too, is a hybrid, just like tiguars or wolfdogs; hence, her parents and society would have the right to domesticate her and keep her captive. The right to tame, own and control is regulated by law, which dictates what animals can become property. In the end, domestication and taming suggest the existence of power relations that undermine the animals' independence.

The same power relations are particularly visible in the art projects that inspired Rosenthal's novel. The cover of Que font les rennes après Noël? features a wolf pacing around a roe deer in a white room - a still from Mircea Cantor's almost three-minute-long film Deeparture (2005), another art project with live animals confined to an artificial space and observed by a human audience. Filmed in Yvon Lambert's gallery in Paris (Cantor 2015), this silent piece invites viewers to enter the gallery space and project their own expectations of the scene (Hirshhorn 2007). Still, animals refuse to participate and do not assume the roles ascribed to them by humans. Just like in the case of Thidet's wolves, Cantor's wolf behaved in a way that baffled onlookers, not attacking the deer but remaining docile and laying down a few feet from it. The wolf is panting and yawning - possible signs of stress - while the deer is sniffing the air and breathing rapidly, visibly distressed yet seemingly calm. "I simply put a deer and a wolf in a room," Cantor says. "There is nothing that is [...] false. [...] We need these real things - to be so, to be there" (Gopnik 2007). The typical predator-prey interplay does not occur here, suggesting that nature, even when closed within four blank walls, is not so easily defined, labeled, and predictable as one would like to think. The ethical problem raised by putting these two animals together in a small space with no regard for their well-being, however, is not acknowledged. While Deeparture aims to show the suspension of basic animal instincts, it actually deepens the divide between humans and animals - a divide that is often reinforced with physical boundaries.

In 2011, Stéphane Thidet explored the confinement of animals in zoos in an installation featuring empty enclosures, titled Vie Sauvage. Two years prior, La Meute did the same thing in reverse by releasing captive animals in an area designed for humans. If a wolf and a deer managed to coexist peacefully in a white cube for two minutes and forty-three seconds, and a pack of six wolves lived in a public park for three months, one wonders if they could also coexist with human audience. From behind fences, walls or screens, predators seem almost domesticated - almost, but not quite. The 
unnatural environment complicates the outcome of both projects. With the story of wolves "reintroduced" to the city, Rosenthal delves deeper into the problematic relationship between humans and animals inhabiting the same urban space.

\section{The Captive Wild}

Traditionally, urbanization processes would leave everything opposed to culture and reason outside city borders, leaving no place for the wild. In this perspective, the "uncivilized" is synonymous with "savage," which applies to both animals and people who strayed from culturally established norms. As Jennifer Wolch argues in "Zoöpolis" (2010 [1998]), cities have maintained this cultural divide. For urban wildlife, as well as pets, livestock, and zoo captives, life in cities means suffering or death; for humans, however, it entails disconnection from nature (221-238). Rosenthal's protagonist is denied any meaningful contact with non-human others. Her only experience of animals is through the television, cinema, books, zoos, and a caged bird. This absence clearly haunts her (Rosenthal 2019, 13-39). The nature/culture dichotomy that is specific to cities produces, according to Wolch, a "radical exclusion of most animals from everyday urban life," which "may disrupt development of human consciousness and identity" (Wolch 2010, 231). Rosenthal's protagonist, desperate for contact with animals, expects to encounter them outside the domesticated territory of the metropolis (Rosenthal 2019, 25); what she finds in the city, however, is not what she was looking for.

"First time [I] saw a wild animal, it was an animal in captivity," the protagonist claims (58). The visit to the Vincennes zoo strips her of all illusions regarding wilderness. She is disappointed by the realness of the animals who seem listless and different from ones in documentary films. She prefers the romanticized notion that the titular reindeer carry rather than seeing specimens in a paddock, fed by man (64). The distance between humans and animals is particularly visible in our attitude towards wildlife parks and zoos - these "constructed environments that often tell us more about ourselves than they do about what we're ostensibly looking at" (Wilson 1992, 246). Wildlife appears more real behind television screens or glass walls of enclosures, where one can see animals first-hand. These expectations about animal behavior are then transferred onto everyday encounters that may not be as romantic and up close and personal (Wolch 2010,230). This begs the question: "can we love what we don't know, what we can't touch?" (Rosenthal 2019, 15).

The novel makes it clear that this dawned-on Rosenthal during her own childhood visit to the Vincennes Zoo. In her article "Je n'irai pas au zoo de Vincennes," she describes the zoo as a theater where people come to watch unwilling animal actors. The facility itself was closed in 2008 for renovation and Rosenthal did not set foot there since. Providing reasons for refusing to visit the reopened Vincennes Zoological Park, the author likens the enclosures to a stage, and the zoo space to a gallery. With its own set design, the zoo hosts a daily spectacle of sorts; les bêtes become part of a live exhi- 
bition, a collection, or an art installation. The shared space for humans and animals is supposedly designed for both sides but in truth its architecture is tailored to the needs of spectators.

What strikes Rosenthal as particularly outrageous is the language adopted by the management of the park, who describe captivity in terms that conceal the reality behind it, refusing to use words that could shock visitors: barbed wire, gates, and containment areas become mild-sounding envelopes, membranes, and shelters. As a space that actually confines one group for the entertainment of another, zoos cater to the human need for a wildness that is subjugated, controlled, and within easy reach (Rosenthal 2014). Veterinarians, stakeholders, and architects, among others, were consulted during the development of this project, but not the one hundred and eighty species of animals housed there.

Throughout Que font les rennes après Noël? Rosenthal $(2019,59)$ provides further objections to zoos, stating that "reasonable living conditions would require that animals remain unobserved." She likens the facilities to prisons, where "captive animals must constantly be visible" (60). Open to the public, zoos offer less privacy to animals than is offered to prisoners. Rosenthal's protagonist also feels incarcerated and under constant surveillance in her room. She wants to evade her parents' gaze (60-62), but there is no escape for her, just like there is no escape for captive wolves kept under the watchful eye of their handlers. To break away, the girl would have to break her silence first. While finding her voice is not easy, this proves even more challenging for animals who cannot speak for themselves.

According to Eva Meijer $(2019,185)$, when humans speak out in the name of animals, as is the case in animal activism, there is a "risk of obscuring their perspective." Nevertheless, interpreting behavior specific to each species can assist those who would seek to support them as another oppressed group. "Those who speak for other animals," writes Meijer, "need to be aware of the power relations involved, and be critical of their own attitudes, privileges, and motives" (195). Olivia Rosenthal resists speaking for animals in her novel, where they are not given a voice. Instead, their agency and their resistance are made evident in the testimonies of others and through parallels between animal and human experiences. "You belong to no one," Rosenthal's protagonist tells herself, though she is convinced she belongs to her mother, just like the wolf pups belong to their handlers (Rosenthal 2019, 47-49); yet, the girl resists captivity, and so do the wolves (50-58).

In her book When Animals Speak, Eva Meijer $(2019,185)$ argues that animal agency is too often disregarded; this "reinforces viewing non-human animals as mute in contrast to human actors, which reaffirms anthropocentrism and unequal power relations." Notably, Jason Hribal (2003) and Eric Baratay (2008, 2012) discuss cases of animal agency manifested through resistance, i.e. refusing to work, retaliating against trainers, and escaping from captivity. Baratay (2012) calls for adopting the animal point of view without anthropomorphism by developing a perspective that would acknowledge animal intellect, emotionality, and needs. Rosenthal's attempt to relate the 
animal experience without speaking for or anthropomorphizing them may be read as a call for rethinking the urban practices that affect the non-human others: not only pets, captives, laboratory and farm animals, but also the wildlife roaming outside and inside the cities.

Jennifer Wolch and Eva Meijer, too, postulate that we rethink our relationship with animals in an urban space. The nature/culture dichotomy, deepened by urbanization, can be overcome by seeking relationships with non-human animals that would acknowledge not only their presence but also agency (Meijer 2019, 149-151). This would entail abandoning the impulse to segregate animals into pests, pets, and commodities, devaluing common species in favor of the rare, endangered, or popular ones (Wolch 2010, 230-231). Since all animals - from dogs to rats and birds - actively transform their habitats, they are not objects but subjects, and ought to be recognized as such. To this end, Wolch $(2010,222)$ proposes a trans-species urban theory that would take into account all animals that live in cities, wild and domestic alike, including urban wildlife, pets as well as farm and laboratory animals. Such a theory, Wolch argues, "is necessary to the development of an ecosocialist, feminist, antiracist urban praxis." She notes that the topic of animal subjectivity is rarely reflected in ecosocialist or feminist practice; establishing meaningful connections between such theories and environmental efforts, however, is a necessary step toward recognizing animals as non-human subjects rather than objects and creating a true trans-species community (224-238). To deconstruct the human-animal divide, it is also crucial to abandon dualistic and hierarchical approaches that devalue others on the grounds of species, race, gender, and sexuality.

\section{The Queer Wild}

One of the earliest connections between feminist, queer, and environmental theories was established by Greta Gaard (1997). In her article "Towards a Queer Ecofeminism," she argues for the importance of feminist and LGBTQ+ liberation movements in environmental efforts. Building on Val Plumwood's (1993) and Karen Warren's (1990) critiques of dualistic thinking and hierarchies, Gaard (1997, 116-118) reads the inferiority of nature to culture, of women to men and of animals to humans as a mutually reinforcing cycle of depreciation that has long functioned in Western society. To dismantle it, the concept of the other has to be questioned. Animals, women, and non-heteronormative identities are defined using dominant elements such as reason, maleness, and heterosexuality, as opposed to nature, femininity, and queerness. Moreover, femininity and nature are linked with the body, emotions, and freedom, which are also subject to exclusion.

Olivia Rosenthal is critical of this depreciative hierarchical approach. In Que font les rennes après Noël? she shows that power relations persist even among the oppressed. The narrator in the novel favors certain species of animals over others, 
preferring wild animals to tame ones. In fact, she feels aversion toward prey - i.e. victims - while her attraction to predators deepens (Rosenthal 2019, 66-67), refusing to identify with animals she deems passive. Her childhood dream to flee with the reindeer is replaced by the desire to run with the panthers when she sees Cat People. After watching the $1942 \mathrm{film}$, she realizes that the expectations she projects are not her own but reflect the expectations society holds over her. As in the case of the audience in Mircea Cantor's Deeparture, the outcome is not one that Rosenthal's protagonist envisioned but appears more satisfying. She soon learns that the film leaves no place for consummation of a heterosexual relationship, and wishes to see the main character, Irena, transform into a panther and devour men. Around the same time, the narrator's attraction to women becomes more evident (116-140).

And yet, to appear "normal" and to secure a sense of belonging, Rosenthal's protagonist does not want to identify with animals anymore. Instead, she wishes to become "humanized," just like a tamed animal would (78-79). Her "desire for humanity is about equal to [her] desire to be an animal; it's impossible to tell the two apart" (143). It is a desire to fit into what society and culture deem "natural." Thus, to become "humanized" is to deny her queer sexuality. The contradictory understanding of what is "natural" dictates that women have to follow their feminine "nature" (understood in categories of procreation and motherhood), and that non-heteronormative persons are acting against that natural order, which implies that nature itself is respected, although in fact it is not (Gaard 1997, 119-120).

In the end, the narrator in Que font les rennes après Noël? embraces her sexuality, which frees her of former constraints. No longer alienated from her body, she assumes an almost predatory role: craving the body of a young woman she has an affair with, as well as craving veal, which she chooses herself before the calf is slaughtered (Rosenthal 2019, 168-183). In a way, she has a greater connection with wildness and freedom than the wolves running in the city and fed frozen chicken (38). Although Olivia Rosenthal does not see lesbians as any more wild or free than other women (which would imply a connection between queerness and marginalization) she nevertheless thinks that their unique relation with society offers certain freedom regarding motherhood, for example (Vallet 2011). In the novel, the decision to oppose heteronormativity is called "betrayal" of society (Rosenthal 2019, 183). Animals are denied this kind of freedom. To "take the sexual drive of the females in hand," the she-wolves in the Nantes pack are sterilized before they can run in the park, a procedure that Rosenthal calls mutilation (33). In a parallel passage, the narrator points out that animal and human sexuality are connected not by way of pleasure but pain. The sexual act is "limited to penetration," silencing and subduing the woman or the female. If "a human form penetrates the area reserved for the animals," however, they risk being devoured, which is both desired and feared (75-78).

Although wild animals entering or even living in cities are neither a rare nor a recent phenomenon, their crossing of this invisible boundary causes fear in the urban community, the intrusion often leading to the death of the animal. Human-wildlife 
conflict is present wherever people come into contact with animals (Woodroffe, Thirgood, and Rabinowitz 2005), and yet in the urban environment it is perhaps perceived as more contemptible than anywhere else because of the division between the civilized and the wild. Urban residents are not used to sharing their territory with wild animals, who are perceived as a nuisance or danger; their presence takes away the sense of relative safety that humans cling to (Wolch 2010, 226). However, since animals are unlikely to leave the urban environment anytime soon, it is perhaps time to look for ways of coexistence.

\section{The Urban Wild}

The title of Rosenthal's Que font les rennes après Noël? asks a childish question: what do reindeer do after Christmas? The question becomes more serious as the child nears adulthood, asking how reindeer fare in the wild (Cruse 2010). The fate of wild wolves is also uncertain. France exterminated its wolves by the 1930s (the last wolf being reportedly killed in 1937), but the turn of the century saw their comeback - not a grand entrance, but a slow trickling from around Europe, across invisible borders. By 2017, wolves were roaming the outskirts of Paris (Mulholland 2017). In early 2020, a couple of wolves were sighted on the streets of Grenoble; taking advantage of low human activity due to the pandemic, the wolves explore vacant urban spaces. Caught on camera near Place aux Herbes, two wolves were seen walking past parked bicycles, benches, and trash bins - an environment that would be familiar to the wolves of Nantes. The animals would certainly not settle there (Mathieu 2020) since, as Olivia Rosenthal notes, "[c]ities are not made for wolves, nor wolves for cities" $(2019,27)$. The presence of wolves roaming the urban infrastructure at night, however, reminds us that we share this planet with other creatures, and that the wild may not be as far removed from city life as we would like to think. At the same time, wildlife does not exist for our entertainment or aesthetic pleasure, although we may develop a respectful relationship with it. "If there has ever been a reason to conserve wolves," Botkin argues $(2004,139)$, "it would seem to lie beyond a direct, practical benefit to people."

In Que font les rennes après Noël? it was "decided against [using] wild wolves, undomesticated wolves or those wolves, known to be dangerous, that roam freely along the border between Italy and France, crossing motorway bridges, taking tunnels and highways, slipping beneath security fences and breaking into sheepfolds," which were left as remnants of the old world (Rosenthal 2019,31). The urban wolves were seen as the safe choice on the path towards domestication. The process has already diminished some species' "otherness"- pets and farm animals have become "so denaturalized, they have come to be seen as part of human culture" (Wolch 2010, 225). Wild animals, however, have been affected since their habitats and behaviors have been modified by human presence and interference (Ritzel and Gallo 2020); "[f]or man, the wolf is no longer a wolf" (Rosenthal 2019, 47). The wolves of Nantes were meant to provide 
aesthetic pleasure and not to "renaturalize" the city or serve conservation purposes. Owners could freely display captive animals and profit from them, selling those they love (49). "Les Loups du Castel," which provided captive wolves for the art installation, was closed in 2016, following the death of its founder, but Francky Estrade was not the only one in the business of keeping wolves for commercial purposes.

"It's the power of the humanity, the ability to control," Cantor argues when asked about the main theme of Deeparture (Ting 2011). The civilized yearn for the wild, but at the same time contain it, as if the wildness were acceptable only in the sphere of imagination or under fully controlled circumstances. Does using captive animals in art projects reflect human superiority or selfish dominion? Thidet's decision to leave the wolves for three months "on display" met with strong opposition. The ethics of using live animals as part of an art installation came under debate. Although these wolves were tame, trained for the purpose of starring in commercials, movies, and live shows, and their basic needs and safety were carefully considered, the idea of exploiting animals in this way remains controversial. Nevertheless, the wolves lived in the moats from June to September.

Perhaps the question we should pose is not whether the art installation is any less ethical than keeping captive animals in a zoo, but whether the breeding and use of animals for the sake of artistic expression and entertainment is ethical, and even more importantly, whether it takes into consideration the animals themselves. As it stands, the animals' well-being is considered only in terms of their basic needs (food, shelter, veterinary care), without accounting for the broader context in which they are used. The wolves of Nantes could hardly teach the public about the behavior, ecology, and conservation of wolves in their natural environment. Quite contrarily, it was the human condition that came under scrutiny. Rosenthal $(2019,90)$ is aware of the chasm that separates humans and animals: "[h]umans have a right to identity, animals don't." Although her protagonist initially identifies with the she-wolves kept in cages (24-25), she eventually achieves independence and realizes that, as much as she had to struggle to find her own voice and break free, she is still above the captive predators who cannot hunt for themselves. The act of choosing the calf at an abattoir effectively separates her from the wolves fed packaged meat from the market. While oppressed human groups continue to fight for their rights, it seems that animals can only pick on frozen poultry. Still, they can show agency, too; occasionally, one would leap over the fence or dig underneath it, break out during the day or slip out in the dead of night, even if for but a moment of freedom. This leap over the boundary between the civilized and the wild, however, should also be made by society in the cultural sphere.

Through her queer ecofeminist theory, Greta Gaard shows that thinking in terms of binary oppositions encourages devaluing one group in favor of another. Jennifer Wolch, followed by Eva Meijer, takes a step further, arguing that segregation occurs even within already oppressed groups as animals tend to be valued according to the aesthetic pleasure they provide, the financial profit they bring, or the damage they cause. Therefore, feminist, queer, and environmental theories and practices can mutually reinforce their efforts to challenge the hierarchical approach to human and non-hu- 
man life. Power relations, after all, begin with silencing differences and denying voice and rights: first to animals, and then according to race, gender, or sexuality. While assisting in the liberation of others, however, the perspective of those who cannot speak for themselves should not be disregarded. To be recognized as equal entails the right to independence, which in turn involves the right to freedom. Equal rights for humans and animals would dictate that wild animals should not be kept in zoological parks or for entertainment purposes. Instead, animals should be allowed to live alongside us, their agency and their rights acknowledged. The human/animal division may still stand in the world described by Rosenthal as a choice that reflects the state of our culture today. It is up to us, however, to redefine that relationship.

\section{References}

Baratay, Éric. 2008. La société des animaux, de la Révolution à la Libération. Paris: La Martinière.

Baratay, Éric. 2012. Le Point de vue animal, une autre version de l'histoire, Paris: Seuil.

Botkin, Daniel B. 2004. Beyond the Stony Mountains: Nature in the American West from Lewis and Clark to Today. New York: Oxford University Press.

Cantor, Mircea (@mirceacantor). 2015. "Today celebrating 10Y since I filmed \#DEEPARTURE in \#Paris at Yvon Lambert Gallery.” Instagram, March 17, 2015. https://www.instagram. com/p/0UZJfwHsLE/

Cruse, Philippine. 2010. "Sous le règne animal d'Olivia Rosenthal." Viabooks. Accessed September 16, 2020. http://www.viabooks.fr/interview/olivia-rosenthal-sous-le-regne-animal-18775.

Deeparture. 2005. Directed by Mircea Cantor.

Gaard, Greta. 1997. “Toward a Queer Ecofeminism," Hypatia 12 (1): 114-115.

Gopnik, Blake. 2007. "The Idea: Predator, Prey, Provocative." Washington Post, October 28, M10.https://hirshhorn.si.edu/wp-content/uploads/2012/03/TWP_MirceaCantor_10.28.pdf.

Hirshhorn. 2007. "Black Box: Mircea Cantor." Hirshhorn Museum. Accessed December 12, 2020. https://hirshhorn.si.edu/exhibitions/black-box-mircea-cantor/.

Klan du Loup. 2009. “'La Meute': une animation sur le Loup, qui se dit 'Oeuvre d'Art.” Klan du Loup. Accessed November 9, 2020. https://www.loup.eu/meute-thidet-animation-loup-art/.

Mai, Joseph. 2016. "Un tissu de mots": Writing Human and Animal Life in Olivia Rosenthal's "Que font les rennes après Noël?" Mosaic 49 (3): 56-62.

Mathieu, Florent. 2020. "Des loups en plein centre-ville de Grenoble à la faveur du confinement?" Place Gre 'Net. Accessed December 12, 2020. https://www.placegrenet.fr/2020/04/01/desloups-en-plein-centre-ville-de-grenoble-a-la-faveur-du-confinement/289206.

Meijer, Eva. 2019. When Animals Speak: Toward an Interspecies Democracy. New York: NYU Press.

Mulholland, Rory. 2017. "Wolves are living on the outskirts of Paris, wildlife groups claim." The Telegraph. Accessed September 16, 2020. https://www.telegraph.co.uk/news/2017/01/17/ wolves-living-outskirts-paris-wildlife-groups-claim/. 
Plumwood, Val. 1993. Feminism and the Mastery of Nature. New York: Routledge.

Ritzel, Kate and Travis Gallo. 2020. "Behavior Change in Urban Mammals: A Systematic Review." Frontiers in Ecology and Evolution 8:576665. doi: 10.3389/fevo.2020.576665.

Rosenthal, Olivia. 2014. "Je n'irai pas au zoo de Vincennes." Le Magazine des écrivains. Accessed November 28, 2020. https://web.archive.org/web/20140720022231/http://www. magazine-litteraire.com/mensuel/544/je-n-irai-pas-au-zoo-vincennes-05-06-2014-123194.

Rosenthal, Olivia. 2019. To Leave with the Reindeer, trans. Sophie Lewis. London: And Other Stories.

Télénantes. 2009. "Nantes: Les loups envahissent les Douves.” Dailymotion. Accessed November 9, 2020. https://www.dailymotion.com/video/x9j9y9.

Thidet, Stéphane. 2009. “La Meute.” Accessed September 16, 2020. http://www.stéphanethidet. com/selected-works/article/la-meute.

Ting, Selina. 2011. “Interview: Mircea Cantor.” InitiArt Magazine. Accessed November 28, 2020. http://web.archive.org/web/20200610063439/http://www.initiartmagazine.com/interview.php?IVarchive $=24$.

Vallet, Romain. 2011. “Olivia Rosenthal: c'est important, le multiple.” Hétéroclite. Accessed September 16, 2020. http://www.heteroclite.org/2011/05/olivia-rosenthal-assises-du-roman-2011-1937.

Warren, Karen. 1990. "The Power and Promise of Ecological Feminism.” Environmental Ethics 12: $125-146$.

Weber, Thierry. 2009. “Album - La Meute de Stephane Thidet." Le blog estuaire Nantes Saint-Nazaire. Accessed November 9, 2020. http://estuaire-nantes-st-nazaire-2007-2011. over-blog.com/album-1400921.html.

Wilson, Alexander. 1992. The Culture of Nature: North American Landscape from Disney to the Exxon Valdez. Cambridge: Blackwell.

Wolch, Jennifer. (1998) 2010. “Zoöpolis.” In Metamorphoses of the Zoo: Animal Encounter after Noah, ed. Ralph R. Acampora, 221-243. Plymouth: Lexington Books.

Woodroffe, Rosie, Simon Thirgood, and Alan Rabinowitz. 2005. "The Impact of Human-Wildlife Conflict on Natural Systems." In People and Wildlife, Conflict or Co-existence?, eds. Rosie Woodroffe, Simon Thirgood, and Alan Rabinowitz, 1-12. Cambridge: Cambridge University Press. 